\section{The use of PTH in the treatment of osteoporosis}

\author{
Uso do PTH no tratamento da osteoporose
}

Victória Z. Cochenski Borba', Nádila Cecyn Pietszkowski Mañas'

\begin{abstract}
SUMMARY
Anabolic drugs have recently widened therapeutic options in osteoporosis treatment, as they influence processes associated with bone formation to a greater extent and earlier than bone reabsortion. They positively affect a number of skeletal properties besides bone density, as intermittent administration of parathyroid hormone (PTH) results in an increase in the number and activity of osteoblasts leading to an increase in bone mass and improvement in skeletal architecture at both the trabecular and cortical bone. Human recombinant parathyroid hormone (hrPTH 1-84) and human recombinant PTH peptide 1-34 (teriparatide) belong to this group. The objective of this paper is to review PTH actions, benefits and adverse effects, action on biochemical markers, combination therapy with antiresorptive agents, impact of antiresorptive therapy prior to anabolic treatment, sequential treatment, and effect on glucocorticoid-induced osteoporosis. Arq Bras Endocrinol Metab. 2010;54(2):213-9
\end{abstract}

Keywords

Osteoporosis; PTH; teriparatide; anabolic

\section{SUMÁRIO}

As drogas anabólicas ampliaram recentemente as opções terapêuticas no tratamento da osteoporose e influenciam em maior escala os processos relacionados com a formação óssea, que ocorrem antes do efeito na reabsorção. Essas drogas afetam um grande número de propriedades esqueléticas, além da densidade mineral óssea. A administração intermitente de PTH leva a um aumento do número e atividade dos osteoblastos, ocasionando aumento da massa óssea e melhora da arquitetura, tanto do osso trabecular quanto cortical. 0 paratormônio recombinante humano (hrPTH 1-84) e o peptídeo recombinante humano 1-34 (teriparatide) pertencem a esse grupo de agentes. 0 objetivo deste artigo é revisar as ações, os benefícios e os efeitos adversos do PTH, assim como sua ação nos marcadores bioquímicos do metabolismo ósseo, a terapia combinada com drogas antirreabsortivas, o impacto do uso dos antirreabsortivos antes do tratamento anabólico, o tratamento sequencial e o tratamento da osteoporose induzida por glicocorticoides. Arq Bras Endocrinol Metab. 2010;54(2):213-9

\section{Descritores}

Osteoporose; PTH, teriparatida, anabólico
1 Serviço de Endocrinologia e Metabologia, Hospital de Clínicas, Universidade Federal do Paraná (SEMPR-UFPR), Curitiba, PR, Brasil

\section{INTRODUCTION}

$\mathrm{A}$ dvances in the management of osteoporosis have been accomplished in the last years. Although a great variety of drugs are available today, treatment of osteoporosis is primarily based on antiresorptive agents, like bisphosphonates; estrogens; the selective estrogen receptor modulator, raloxifene; calcitonin and strontium ranelate. The mechanisms of action differ within and between these classes of drugs, but inhibition of osteoclast-mediated bone reabsortion can be considered a final common pathway (1).

Anabolic drugs have recently widened therapeutic options, as they influence processes associated with bone formation to a greater extent and earlier than bone reabsortion. Anabolic agents positively affect a number of skeletal properties besides bone density (2). Human recombinant parathyroid hormone (hrPTH 1-84) and human recombinant PTH peptide 1-34 (teriparatide) belong to this group of agents. 
PTH is produced by the parathyroid glands and plays a major role in the regulation of calcium and phosphate metabolism. A continuous endogenous production or exogenous administration of PTH as is the case in primary or secondary hyperparathyroidism can lead to deleterious consequences to the skeleton, particularly for cortical bone. However, intermittent administration of PTH results in an increase in the number and activity of osteoblasts leading to an increase in bone mass and improvement in skeletal architecture at both trabecular and cortical bone (3). Osteoblasts, bone lining cells, and bone marrow stromal cells have PTH receptors, and intermittent PTH stimulates these cells through the modulation of cAMP concentrations and cAMP-dependent protein kinase A. The PTH receptor also activates the calcium protein kinase $\mathrm{C}$ pathway, stimulating proliferation of cells in the osteoblastic lineage (4). Additional mechanisms of PTH signal propagation and control include internalization of the PTH receptor its association with importins and its nuclear translocation, where it may regulate gene transcription. The exact signaling pathway responsible for the anabolic effect is not known, but the various pathways used by PTH may determine whether it has anabolic or catabolic actions. The Wnt- $\beta$-catenin pathway has generated interest because the expression of Wnt antagonist sclerostin is down-regulated by PTH, and this may partially account for the anabolic actions of PTH. The molecule teriparatide (TPTD) exerts its anabolic effect at least in part by stimulating the MAPK, phospholipase $\mathrm{A}$ and $\mathrm{D}$ pathways and, thus, modulating differentiation, proliferation, and activity of osteoblast pool, stimulating differentiation and activation of quiescent lining cells, increasing the life span of osteoblasts and osteocytes by inhibiting their apoptosis. Some of these effects are mediated by activation of other pathways, like Runx2, or modulation of synthesis and release of local mediators including Wnt, BMPs, TGF-b, IGF-1, FGF-2 and IL-6 $(4,5)$ (Figures $1 \mathrm{~A}$ and $\mathrm{IB}$ ).

\section{BENEFICIAL EFFECTS OF PTH TREATMENT}

There were statistically significant benefits from using teriparatide $20 \mathrm{mcg}$, in relation to placebo, considering the following outcomes: reduction in the number of new vertebral fractures (relative risk (RR) 0.35); reduction in the number of new non-vertebral fractures (RR 0.54); increased whole-bone density (RR 3.1), increased lumbar BMD (RR 9.6); increased femoral

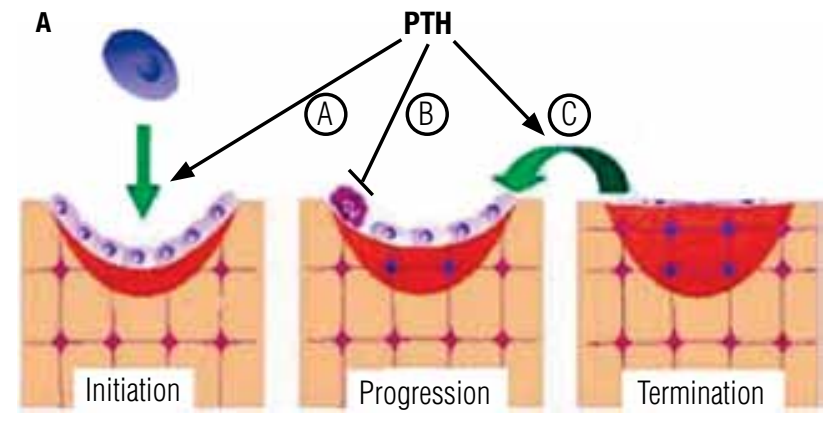

B

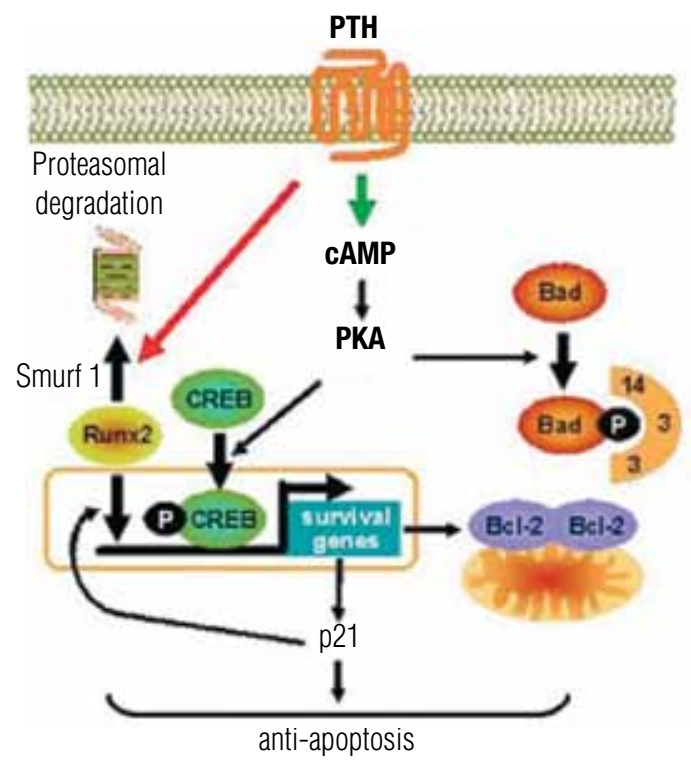

Figure 1. Mechanism involved in the anabolic effect of PTH. A. PTH increases osteoblast number (A) by increasing the development of osteoblast, $(B)$ inhibiting osteoblast apoptosis, and $(C)$ reactivating lining cells to resume their matrix synthesizing function. B. Shows the antimitotic effect of PTH on osteoblast progenitors and apoptosis induction. These effects account for the regulation of growth factors produced locally or released from the bone matrix and concomitantly show the increase in osteoblast number through its effect of preventing adipocyte differentiation. Adapted from Jilka (5).

BMD (RR 3.6) (6). Further post hoc analysis of this cohort demonstrated that the fracture risk reduction was largely independent of age and initial BMD (7).

Monitoring of osteoporosis therapy based solely on dual energy X-ray absortiometry (DXA) is insufficient to assess anti-fracture efficacy, and it is already known that PTH has important benefits on bone quality (8). Treatment with teriparatide leads to bone strength increases for different loading conditions of about 30\% (9).

The beneficial effects of TPTD on bone qualities are seen in cancellous skeleton. At the cortical site, PTH does not typically increase bone density and there may 
be a small decline in BMD in association with an increase in cortical porosity. However, this does not translate into decreased bone strength because porosity only occurs in the inner one-third of bone, where mechanical effect is minimal. Other salutary effects occur at cortical bone, such as: periosteal apposition, increased cortical area, cortical thickness and cross-sectional area (10).

Animal experiments show a dramatic improvement of skeletal repair by teriparatide. Postmenopausal women with a distal radial fracture in need of closed reduction, but not surgery, were assigned to eight weeks of teriparatide; median time to complete cortical bridging was analyzed, and time to heal was shorter than placebo. Acceleration of fracture repair was shown, but this data needs further studies (11). Teriparatide can significantly reduce the occurrence of new adjacent and nonadjacent vertebral fractures (12), and yet women on TPTD who lost neck BMD still had significant reductions in vertebral fracture risk (13). There was also an improvement in emotional functioning, relating to fear of falling, alleviation of pain symptoms and improvement in health-related quality of life in this osteoporosis treated patients (14).

\section{EFFECTS ON BIOCHEMICAL MARKERS}

Studies have shown that teriparatide induces large increases in biochemical markers of bone formation after one month of therapy followed by a delayed increase in bone resorption markers, with important implications for monitoring patients treated with this drug (15). This difference in the rise of bone markers produces what has been termed "the anabolic window", a period when bone formation is greater than bone resorption (16) Figure 2. A study published by Glover and cols. (17) showed a rapidly and robust increase of PINP (type I collagen C-terminal propeptide) during the first two days of teriparatide of $8.2 \%$ and continued until the end of treatment in 28 days to $110 \%$. Osteocalcin (OC) showed a similar but less pronounced pattern. PINP, OC and bone alkaline phosphatase (bone ALP) increased at least $75 \%$ at the end of treatment (17).

Another study comparing risedronate versus teriparatide on bone turnover markers in women with postmenopausal osteoporosis showed reduction in PINP, CTX (C-terminal telopeptide of type 1 collagen), and total ALP levels in the risedronate group and increased in the teriparatide group throughout the one year treatment, as it would be expected (18).

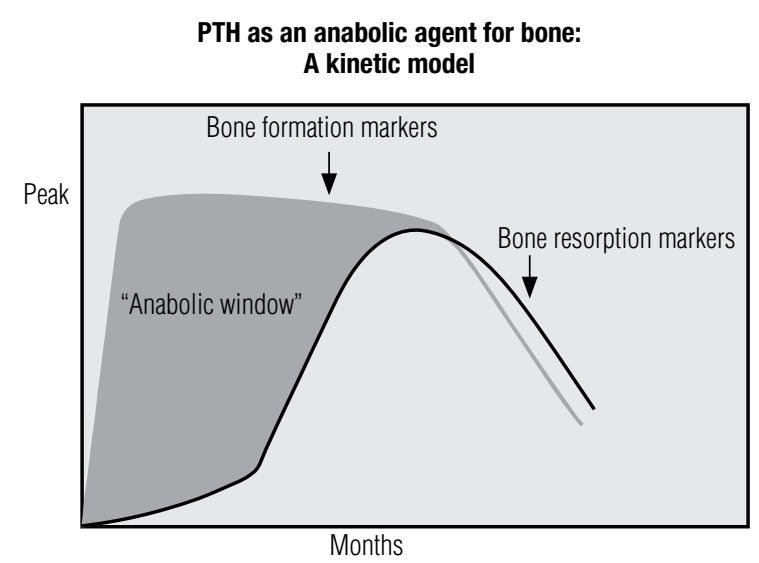

Figure 2. PTH anabolic window. The anabolic window is based on the bone marker response to PTH and is the time of its maximum anabolic effect. Adapted from Rubin and Bilezikian with permission (16).

\section{CONCURRENT THERAPY WITH AN ANTIRESORPTIVE AGENT}

It was considered that giving an antiresorptive agent may increase the anabolic window by preventing the increase in bone resorption with teriparatide treatment, but bisphosphonate administration may affect PTH response. The studies of Black and cols. (19) and Finkelstein and cols. (20) showed smaller increases in BMD by QCT and in antiresorptive response in the bone turnover markers following the concurrent use of alendronate and PTH (1-84) and teriparatide respectively. It is postulated that frequent bisphosphonate exposure inhibits protein prenylation in preosteoblasts, and thus reduces the ability of PTH to activate bone-lining cells into matrix-secreting osteoblasts, a crucial step in the early bone anabolic response to PTH. Other antiresorptive agents, such as estrogen and raloxifene do not appear to blunt this anabolic effect (21).

\section{CYCLIC THERAPY OF TERIPARATIDE}

Cosman and cols. (22) reported the results of 2 studies where TPTD were given cyclically. In the first study, women with osteoporosis continued on alendronate and received cyclic TPTD, daily treatment of 3 months on $/ 3$ months off for 15 months, produced similar BMD effects (by DXA) to daily continued TPTD, despite the fact that only $60 \%$ of the total TPTD dose was given. In the second study, 139 postmenopasual women with osteoporosis by BMD who were either treatment-naïve $(n=67)$ or on prior alendronate treatment for at least $\mathrm{l}$ year $(\mathrm{n}=72)$ received cyclic versus daily 
TPTD over a 2 -year treatment period. Preliminary results showed that there were no significant differences in BMD change at either skeletal site between the cyclic and daily treatments within either group (alendronatetreated or treatment-naïve), suggesting that the cyclic approach may be preferable to daily TPTD administration, to increase BMD in both alendronate-treated and treatment-naïve women $(22)$.

\section{IMPACT OF ANTIRESORPTIVE PRIOR TERIPARATIDE TREATMENT}

Concurrent use of bisphosphonate therapy reduces the anabolic effect of teriparatide. Consequently, in clinical practice bisphosphonates could be discontinued and teriparatide held for a few months to allow bone turnover to increase. Keel and cols. (23) carried out a study to evaluate the effect of wash-out on treatment response to teriparatide after bisphosphonate and naïve patients, who were followed prospectively over 12 months. The magnitude of the increase in bone markers was comparable in both patient groups irrespective of prior bisphosphonate exposure; similarly, increases in BMD after 12 months were not significantly different between treated and naïve patients. Besides this, the response of teriparatide was not related to the duration of bisphosphonate wash-out (median duration 4.2 months). In this study, wash-out does not appear to influence treatment effect and teriparatide therapy can be started immediately after ceasing bisphosphonate therapy (23).

Suppression of bone turnover by bisphosphonates is associated with increased bone microdamage accumulation in animal models. A study investigated the effects of teriparatide treatment on changes in microdamage accumulation at the iliac crest in previously treatment-naive patients or in those switched from alendronate to teriparatide. Teriparatide reduces microdamage accumulation in patients previously treated with alendronate (24).

Comparing raloxifene with alendronate used 18 months or more, prior or added to teriparatide treatment, in postmenopausal women, greater bone turnover increases were achieved by switching to teriparatide, while greater BMD increases were achieved by adding teriparatide (25).

It is possible, that it is not the specific antiresorptive used prior to teriparatide that dictates the subsequent densitometric response but rather the extent to witch bone turnover is reduced (2).

\section{SEQUENTIAL TREATMENT AFTER TERIPARATIDE}

Sequential treatment with an antiresorptive agent is believed to preserve or further increase BMD, as TPTD is approved in most countries for a treatment period of 18-24 months. It is unclear which therapy should be given after stopping teriparatide for osteoporosis. After medication is stopped, the decline in BMD is greater in women than in men (26). EUROFORS study compared BMD effects and clinical safety of continued teriparatide to complete 24 months or follow-up treatment after 1 year of teriparatide with raloxifene or no active treatment. Patients receiving raloxifene in year 2 had no further change in spine BMD from year 1 (change from baseline, $7.9 \%$ ) whereas no active treatment had a BMD decrease of $2.5 \%$ in year 2 (change from baseline, $+3.8 \%$ ). At total hip, BMD increases from baseline at 2 years were of $2.5 \%$ with teriparatide, $2.3 \%$ with raloxifene and $0.5 \%$ with no active treatment. BMD increases progressively over 2 years of teriparatide treatment in women with severe osteoporosis and after discontinuation of teriparatide, raloxifene maintains spine BMD and increases hip BMD (27).

Strontium ranelate (SR) is thought to uncouple bone remodeling resulting in increased BMD and reduced fracture risk, and SR following TPTD administration further increases BMD and could represent an effective sequential treatment (28).

\section{GLUCOCORTICOID-INDUCED OSTEOPOROSIS (GIOP)}

Glucocorticoids affect both trabecular and cortical bone and a vertebral fracture can be the first symptom of the GIOP, therefore, efficacious therapies are needed to counter their deleterious effects on the skeleton. Current guidelines for GIOP management recommend bisphosphonates, especially alendronate and risedronate as first line agents for GIOP, and guidelines propose the preventive use of bisphosphonates early in the course of glucocorticoid (GC) therapy in high-risk patients.

More recently, efficacy data have demonstrated that teriparatide is an efficacious treatment for patients with GIOP compared with an approved treatment, such as alendronate (29). At 18 months, increases in lumbar spine BMD were significantly greater in the teriparatide versus alendronate group in postmenopausal women (7.8\% vs. $3.7 \%, \mathrm{p}<0.0001)$, premenopausal women $(7.0$ vs. $0.7 \%, \mathrm{p}<0.001)$, and men $(7.3 \%$ vs. $3 . \%$, $\mathrm{p}=0.03)(30)$. Due to the results obtained in clinical trials, teriparatide has recently received an indication for GIOP and label indication has also been expanded (4). 


\section{ADVERSE EVENTS OF PTH TREATMENT}

The following side effects were more frequent in the teriparatide group than in the placebo group: headache (RR 1.4), nausea (RR 2.34), cramps (RR 3.22) and hypercalcemia (RR 9.73) (6).

PTH induces hypercalcemia by its own mechanism of action increasing bone turnover, which may mobilize skeletal calcium stores; increase renal production of 1,25-dihydroxyvitamin $\mathrm{D}$, which increases gastrointestinal absorption; and increase the renal tubular reabsorption of calcium. At Fracture Prevention Trial (FPT), hypercalcemia (above $10.6 \mathrm{mg} / \mathrm{dL}$ ) was seen in $11 \%$ of the patients administrated $20 \mathrm{mcg} /$ day teriparatide soon after administration (4 to 6 hours) and consecutive hypercalcemia was observed in $3 \%$ and was not sustained (5). The FDA (Food and Drug Administration) has no recommendation for monitoring the serum calcium in these patients, however, there are some questions to be considered. 1) Observe the calcium and vitamin $\mathrm{D}$ intake including total dietary and supplemental intake; 2) Serum calcium should be checked at least once in the first month after starting the therapy. If hypercalcemia occurs, repeat the calcium measurement in 1 to 2 days, if persistent, calcium intake could be reduced or stop teriparatide and recheck serum calcium in 7 to 10 days (31).

Hypercalciuria has a small risk of occurrence and decisions regarding teriparatide effects on urinary calcium excretion must be interpreted in the context of total clinical picture. Patients with renal stones or hypercalciuria before treatment should be investigated from a metabolic standpoint, define the cause and correct it as a first step. Monitoring calcium excretion is not recommended in patients with no renal stones or normal basal urinary calcium (31).

In the FPT serum uric acid increased above the upper limit of normal (range $=13 \%$ to $20 \%$ of the teriparatide treated group) without any incidence of gout and there is no guidance regarding management of patients with uric acid disorders, so, clinical judgment must prevail.

Since its approval by theFDA in December 2002, teriparatide has been safely used by more than 600,000 patients (31). There was a concern that teriparatide might increase the risk for patients to develop osteosarcoma, as almost $45 \%$ of the rats treated with this drug at the highest-tested dose level developed this aggressive form of bone cancer. There are two cases of patients who have received teriparatide treatment for osteoporosis and possibly developed osteosarcoma, but in these cases other risk factors were present, such as prior radiation exposure which must be questioned before clinical use of the drug (32). Balancing the proven benefits of teriparatide shown by clinical trials with the theoretical risk for teriparatide-induced osteosarcoma, the FDA mandated both a black-box warning and a company postmarketing surveillance program (33).

Therefore, this medication must continue to be contraindicated for patients who are at risk of developing osteosarcoma, such as those with unexplained high phosphatase alkaline levels, Paget's disease, or those who have undergone irradiation on the bones. Moreover, it must be contraindicated for patients with hypercalcemia or hyperparathyroidism (34).

\section{PTH ANALOGS}

Full-length recombinant human PTH (1-84) has been investigated in the management of postmenopausal osteoporosis. It has been postulated that the C-terminal region of $\mathrm{PTH}$, which teriparatide lacks, also has biological functions in the bone that are mediated by a receptor specific for this region of the hormone. Research suggests that PTH 1-84 is likely not to have an association with osteosarcoma in rats due to the pro-apoptotic effects of C-terminal PTH fragments that maintain normal bone cell turnover (3).

No comparative studies exist between PTH 1-34 and PTH 1-84, so no clear pronouncements can be made about the potential differences in effectiveness and safety. As regards the efficacy, a convincing reduction of vertebral fractures was shown in both cases and a reduction of non-vertebral fractures was shown in the case of PTH 1-34 only. Another significant resemblance is that both have a strong anabolic action. As regards the side effect profile, PTH 1-84 appears to have higher incidence of hypercalcemia, hypercalciuria and nausea than teriparatide, but these differences could be ascribed to differences in definitions and/or patient populations (35).

\section{TRANSDERMAL TERIPARATIDE ADMINISTRATION}

A novel transdermal patch, providing rapid pulse delivery of TPTD, may provide a desirable alternative to daily subcutaneous (s.c.) teriparatide injections. A study with 165 postmenopausal women with osteoporosis was realized to determine the safety and efficacy of transdermal TPTD patch compared to placebo patch 
and s.c. TPTD 20-microg injection. A TPTD patch with a $20-, 30-$, or 40 -microg dose or a placebo patch was self-administered daily for 30-min wear time, or 20 microg of TPTD was injected daily during 6 months. TPTD delivered by transdermal patch significantly increased lumbar spine BMD versus placebo patch in a dose-dependent manner at 6 months $(\mathrm{P}<0.001)$. TPTD 40-microg patch increased total hip BMD compared to both placebo patch and TPTD injection $(\mathrm{P}<0.05)$. All treatments were well tolerated, and no prolonged hypercalcemia was observed (36).

\section{COST-EFFECTIVENESS OF TERIPARATIDE TREATMENT}

A recent cost-effectiveness analysis from Sweden suggested that teriparatide may be cost-effective compared with no treatment (37). Teriparatide may prevent fractures in comparison to alendronate in women with severe osteoporosis, although it is more expensive. Liu and cols. (38) evaluated cost-effectiveness of usual care (UC) calcium and vitamin D supplementation with 3 strategies of therapy plus UC: alendronate therapy alone, teriparatide alone, and teriparatide followed by alendronate. Postmenopausal white women with severe osteoporosis were evaluated. Teriparatide alone is more expensive and produces a smaller increase in quality-adjusted lifeyear (QALY) than therapy with alendronate. Sequential teriparatide/alendronate therapy appears expensive but could become more cost-effective with reductions in teriparatide price, restriction of use in high-risk women, or if short courses of teriparatide could provide the same fracture reduction efficacy as those reported in longer clinical trials (38). These data are limited to treatmentnaive women and may not be applicable to patients receiving treatment for osteoporosis.

\section{CONCLUSION}

Teriparatide is an anabolic therapy that improves bone density, reduces vertebral and nonvertebral fracture incidence, and improves geometric and microarchitectural properties of bone, approved for the treatment of osteoporosis in postmenopausal women and in men at high risk for fracture. It should be considered as firstline therapy in patients at high risk for fracture, or in patients for whom the physician is not satisfied with the effectiveness of other registered therapies (31). Patients who experience a fracture on antiresorptive therapy are also eligible for treatment with teriparatide, which is also the case in treatment-naïve patients with prevalent fracture and glucocorticoid-induced osteoporosis (21). Overall, teriparatide is very well tolerated and safe in most patients.

Disclosure: no potential conflict of interest relevant to this article was reported.

\section{REFERENCES}

1. Pleiner-Duxneuner J, Zwettler E, Paschalis E, Roshger P, NellDuxneuner V, Klaushofer K. Treatment of osteoporosis with parathyroid hormone and teriparatide. CalcifTissue Int. 2009;84:159-70.

2. Girotra M, Rubin MR, Bilezikian JP. Anabolic skeletal therapy for osteoporosis. Arq Bras Endocrinol Metab. 2006;50:745-54.

3. Neuprez A, Reginster JY. Bone-forming agents in the management of osteoporosis. Best Pract Res Clin End Met. 2008;22:869-83.

4. Migliaccio S, Brama M, Malavolta N. Management of glucocorticoids-induced osteoporosis: role of teriparatide. Ther Clin Risk Manag. 2009;5:305-10.

5. Jilka RL. Molecular and cellular mechanisms of the anabolic effect of intermittent PTH. Bone. 2007;40:1434-46.

6. Neer RM, Arnaud CD, Zancheta JR, Prince R, Gaich GA, Reginster $J Y$, et al. Effect of parathyroid hormone (1-34) on fractures and bone mineral density in postmenopausal women with osteoporosis. N Engl J Med. 2001;344(19):1434-41.

7. Marcus $R$, Wang $O$, Satterwhite J, Mitlak B. The skeleton response to teriparatide is largely independent of age, initial bone mass density, and prevalent vertebral fractures in postmenopausal women with osteoporosis. J Bone Miner Res. 2003;18(1):18-23.

8. Lindsay R, Miller P, Pohl G, Glass EV, Chen P, Krege JH. Relationship between duration of teriparatide therapy and clinical outcomes in postmenopausal women with osteoporosis. Osteoporos Int. 2009;20(6):943-8.

9. Graeff C, Chevalier Y, Chalebois M, Varga P, Pahr D, Nickelsen TN, et al. Improvements in vertebral body strength under teriparatide treatment assessed in vivo by finite element analysis: results from EUROFORS study. J Bone Miner Res. 2009;24:1672-80.

10. Burr DB, HiranoT, Turner $\mathrm{CH}$, Hotchkiss $\mathrm{C}$, Brommage $\mathrm{R}$, Hock JM. Intermittently administered human parathyroid hormone (1-34) treatment increases intracortical bone turnover and porosity without reducing bone strength in the humerus of ovariectomized cynomolgus monkeys. J Bone Miner Res. 2001;16(1):157-65.

11. Aspenberg P, Genat HK, Johansson T, Nino AJ, Krohn K, GarciaHernadez PA, et al. Teriparatide for acceleration of fracture repair in humans: a prospective, randomized, double-blind study of 102 postmenopausal women with distal radial fractures. J Bone Min Res. 2009 Jul 13 [Epub ahead of print]

12. Bouxsein ML, Chen EV, Glass EV, Kallmess DF, Delmas PD, Mitlak $\mathrm{BH}$. Teriparatide and raloxifene reduce the risk of new adjacent vertebral fractures in postmenopausal women with osteoporosis. Results from two randomized controlled trials. J Bone Joint Surg Am. 2009;91(6):1329-38.

13. Watts NB, Miller PD, Kohlmeier LA, Sebba A, Chen P, Wong M, et al. Vertebral fracture risk is reduced in women who loss femoral neck BMD with teriparatide treatment. J Bone Miner Res. 2009;24(6):1125-31.

14. Lau AN, Ali SH, Sawka AM, Thabane L, Papaionnou A, Gafni A, et al. Improvement in health-quality of life in osteoporosis patients treated with teriparatide. BMC Musculoskelet Disord. 2008;7(9):151. 
15. Recker RR, Marin F, Ish-Shalom S, Moricke R, Hawkins F, Kapetanos $G$, et al. Comparative effects of teriparatide and strontium ranelate on bone biopsies and biochemical markers of bone turnover in postmenopausal women with osteoporosis. J Bone Miner Res. 2009;24(8):1354-7.

16. Rubin MR, Bilezikian JP. New anabolic therapies in osteoporosis. Endocrinol Metab Clin North Am. 2003;32:285-308.

17. Glover SJ, Eastell R, McCloskey EV, Rogers A, Garnero P, Lowery $\mathrm{J}$, et al. Rapid and robust response of biochemical markers of bone formation to teriparatide therapy. Bone. 2009;45(6):1053-8.

18. Anastasilakis AD, Goulis DG, Polyzos SA, Gerou S, Koukolis GN, Efstathiadou Z, et al. Head-to-head comparison of risedronate versus teriparatide on bone turnover markers in women with postmenopausal osteoporosis: a randomized trial. Int J Clin Pract. 2008;62(6):919-24.

19. Black DM, Greenspan SL, Ensrud KE, Palermo L, Mc Gowan JA, Lang TF, et al. The effects of parathyroid hormone and alendronate alone or in combination in postmenopausal osteoporosis. $\mathrm{N}$ Engl J Med. 2003;349(13):1207-15.

20. Finkelstein JS, Haves A. Hunzelan JL, Wyland JJ, Lee H, Meer RM. The effects of parathyroid hormone and alendronate, or both in men with osteoporosis N Engl J Med. 2003;349(13):1216-26.

21. File E, Deal C. Clinical update on teriparatide. Curr Rheumat Rep. 2008;11:169-76.

22. Cosman F, Nieves J, Dempster D, Lindsay R. Cyclic vs daily teriparatide therapy in previously untreated postmenopasual women and in those on prior alendronate. ASBMR 31st Annual Meeting. A0 9002528.

23. Keel C, Kraenzlin ME, Kraenzlin CA, Muller B, Meier C. Impact of bisphosphonate wash-out prior to teriparatide therapy in clinical practice. J Bone Min Metab. 2009 Jun 17 [Epub ahead of print]

24. Dobnig H, Stepan JJ, Burr DB, Li J, Michalská D, Sipos A, et al. Teriparatide reduces bone microdamage accumulation in postmenopausal women previously treated with alendronate. J Bone Min Metab. 2009 May 19 [Epub ahead of print]

25. Cosman F, Wermers RA, Macuk KF, Xie L, Glass EV, Krege JH. Effects of teriparatide in postmenopausal women with osteoporosis on prior alendronate or raloxifene: differences between stopping and continuing the antireabsortive agent. J Clin Endocrinol Metab. 2009;94(10):3772-80.
26. Leder BZ, Neer RM, Wyland JJ, Lee HW, Burnerr-Bowie SA, Finkelstein JS. Effects of teriparatide treatment and discontinuation in postmenopausal women and eugonadal men with osteoporosis. J Clin Endocrinol Metab. 2009;94(8):2915-21.

27. Eastell R, Nickelsen T, Marin F, Barker C, Hadji P, Farrerons J, et al. Sequential treatment of severe postmenopausal osteoporosis after teriparatide: final results of the randomized, controlled European Study of Forteo (EUROFORS). J Bone Miner Res. 2009;24(4):726-36.

28. Anastasilakis AD, Polyzoz Sa, Avramidis A, Papatheodorou A, Terpos $E$. Effect of strontium ranelate on lumbar spine bone mineral density in women with established osteoporosis previously treated with teriparatide. Horm Metab Res. 2009;41(7):559-62.

29. Saag KG, Shane E, Boonen S. Teriparatide or alendronate in glucocorticoid-induced osteoporosis. N Engl J Med. 2007;357:2028-39.

30. Langdahl BL, Marin F, Shane E, Dobnig H, Zanchetta JR, Maricic $M$, et al. Teriparatide versus alendronate for treating glucocorticoid-induced osteoporosis: an analysis by gender and menopausal status. Osteoporos Int. 2009 Apr 7 [Epub ahead of print]

31. Miller PD. Safety of parathyroid hormone for treatment of osteoporosis. Curr Osteoporos Rep. 2008;6:12-6.

32. Harper K, Frege JH, Marcus R, Mitlak BH. Osteosarcoma and teriparatide? J Bone Miner Res. 2007;22:334.

33. Subbiah V, Madsen VS, Raymond AK, Benjamin RS, Ludwig JA. Of mice and men: divergent risks of teriparatide-induced osteosarcoma. Osteoporosis Int. 2009 Jul 14 [Epub ahead of print]

34. Trevisani VFM, Riera R, Imato AM, Saconato H, Atallah AN. Teriparatide in postmenopausal women with osteoporosis: systematic review. Sao Paulo Med J. 2008;126(5):279-84. Review.

35. Verhaar HJ, Lems WF. PTH-analog: comparable or different? Arch Gerontol Geriatr. 2009;49(2):130-2.

36. Cosman F, Lane NE, Bolognese MA, Zanchetta JR, Garcia-Hernadez PA, Sees K, et al. Effect of transdermal teriparatide administration on bone mineral density in postmenopausal women. J Clin Endocrinol Metab. 2010;95(1):151-8.

37. Lunkdvist J, Johnell O, Cooper C, Sykes D. Economic evaluation of parathyroid hormone in the treatment of osteoporosis in postmenopausal women. Osteoporos Int. 2006;17:201-11.

38. Liu H, Michaud K, Nayak S, Karpf DB, Owens DK, Garber AM. The cost-effectiveness of therapy with teriparatide and alendronate in women with severe osteoporosis. Arch Intern Med. 2006;166(11):1209-17. 